\title{
Production of 2,3-butanediol from glucose and cassava hydrolysates by metabolically engineered industrial polyploid Saccharomyces cerevisiae
}

\author{
Ye-Gi Lee and Jin-Ho Seo* (1)
}

\begin{abstract}
Background: 2,3-Butanediol (2,3-BDO) is a valuable chemical for industrial applications. Bacteria can produce 2,3-BDO with a high productivity, though most of their classification as pathogens makes them undesirable for the industrial-scale production. Though Saccharomyces cerevisiae (GRAS microorganism) was engineered to produce 2,3BDO efficiently in the previous studies, their 2,3-BDO productivity, yield, and titer were still uncompetitive compared to those of bacteria production. Thus, we propose an industrial polyploid S. cerevisiae as a host for efficient production of 2,3-BDO with high growth rate, rapid sugar consumption rate, and resistance to harsh conditions. Genetic manipulation tools for polyploid yeast had been limited; therefore, we engineered an industrial polyploid S. cerevisiae strain based on the CRISPR-Cas9 genome-editing system to produce 2,3-BDO instead of ethanol.
\end{abstract}

Results: Endogenous genes coding for pyruvate decarboxylase and alcohol dehydrogenase were partially disrupted to prevent declined growth rate and $\mathrm{C}_{2}$-compound limitation. A bacterial 2,3-BDO-producing pathway was also introduced in engineered polyploid S. cerevisiae. A fatal redox imbalance was controlled through the heterologous NADH oxidase from Lactococcus lactis during the 2,3-BDO production. The resulting strain (YG01_SDBN) still retained the beneficial traits as polyploid strains for the large-scale fermentation. The combination of partially disrupted PDC (pyruvate decarboxylase) and $A D H$ (alcohol dehydrogenase) did not cause the severe growth defects typically found in all pdc-or adh-deficient yeast. The YG01_SDBN strain produced $178 \mathrm{~g} / \mathrm{L}$ of 2,3-BDO from glucose with an impressive productivity $(2.64 \mathrm{~g} / \mathrm{L} \mathrm{h})$. When a cassava hydrolysate was used as a sole carbon source, this strain produced $132 \mathrm{~g} / \mathrm{L}$ of 2,3-BDO with a productivity of $1.92 \mathrm{~g} / \mathrm{L} \mathrm{h}$.

Conclusions: The microbial production of 2,3-BDO has been limited to bacteria and haploid laboratorial S. cerevisiae strains. This study suggests that an industrial polyploid S. cerevisiae (YG01_SDBN) can produce high concentration of 2,3-BDO with various advantages. Integration of metabolic engineering of the industrial yeast at the gene level with optimization of fed-batch fermentation at the process scale resulted in a remarkable achievement of 2,3-BDO production at $178 \mathrm{~g} / \mathrm{L}$ of 2,3-BDO concentration and $2.64 \mathrm{~g} / \mathrm{L} \mathrm{h}$ of productivity. Furthermore, this strain could make a bioconversion of a cassava hydrolysate to 2,3-BDO with economic and environmental benefits. The engineered industrial polyploid strain could be applicable to production of biofuels and biochemicals in large-scale fermentations particularly when using modified CRISPR-Cas9 tools.

Keywords: Industrial yeast, Polyploid Saccharomyces cerevisiae, 2,3-Butanediol, CRISPR-Cas9, Cassava hydrolysate

\footnotetext{
*Correspondence: jhseo94@snu.ac.kr

Department of Agricultural Biotechnology and Center for Food

and Bioconvergence, Seoul National University, Seoul 08826, Republic

of Korea
}

(c) The Author(s) 2019. This article is distributed under the terms of the Creative Commons Attribution 4.0 International License (http://creativecommons.org/licenses/by/4.0/), which permits unrestricted use, distribution, and reproduction in any medium, provided you give appropriate credit to the original author(s) and the source, provide a link to the Creative Commons license, and indicate if changes were made. The Creative Commons Public Domain Dedication waiver (http://creativecommons.org/ publicdomain/zero/1.0/) applies to the data made available in this article, unless otherwise stated. 


\section{Background}

The emerging platform materials of $\mathrm{C} 2-\mathrm{C} 4$ diol isomers have been studied for production from renewable resources. Especially, 2,3-butanediol (2,3-BDO) is a promising chemical with various industrial applications [1]. It is used in the production of a wide range of needed derivatives, such as softening agents, plasticizer, polyester, drugs, and cosmetics [2, 3]. In addition, 2,3-BDO can be used as a starting material for chemical conversion, especially for production of 2-butanone (commonly methyl ethyl ketone or MEK) and 1,3-butadiene. MEK considered as an effective liquid-fuel additive and 1,3-butadiene used to produce the synthetic rubber are the major building blocks in the chemical industry $[4,5]$. It has been attempted that the promising platform materials can be produced in the engineered microorganism to apply large-scale fermentation. For instance, a biotechnology company of Genomatica (San Diego, USA) constructed a commercial pipeline for producing 1,4-BDO as much as 30,000 ton/year via the engineered Escherichia coli [6]. The 2,3-BDO market need is expected to reach 74 kilotons by 2018 [7] and the estimated annual global market value of 2,3-BDO derivatives is approximately 43 billion dollars [4]. Thus, global demand of industrial-scale production of 2,3-BDO from biomass is increasing [8].

Petroleum-based chemical processes currently dominate commercial 2,3-BDO production [9]. Due to future global regulation of carbon dioxide emissions, scientists suggest that microbial production of 2,3-BDO could be a powerful alternative if the current low productivity and high production cost could be overcome. Microbial production of 2,3-BDO using bacterial species such as Enterobacter and Klebsiella is typically done owing to a fast growth in nutrient-poor media and the native 2,3-BDO-producing ability. For large-scale production, an inexpensive and abundant carbon source is one of the most important prerequisites. Therefore, previous efforts have used various biomass hydrolysates in the production 2,3-BDO. In one example, a research group tried to delete $p f l B$ (pyruvate formate-lyase) and $p t s G$ (glucose permease of the phosphotransferase system) in Enterobacter aerogenes to increase their use of the mixed sugars in lignocellulosic hydrolysates. When a sugarcane bagasse hydrolysate was provided as a carbon source, the engineered $E$. aerogenes produced approximately $20 \mathrm{~g} / \mathrm{L}$ 2,3-BDO (0.395 g 2,3-BDO/g carbon source) in $72 \mathrm{~h}$ [10]. Another engineered strain of E. cloacae produced $152 \mathrm{~g} / \mathrm{L}$ 2,3-BDO within $44 \mathrm{~h}$ from lignocellulose-derived sugars [11]. In addition, other research group engineered Klebsiella pneumonia SDM using the strategy of random mutagenesis to produce $150 \mathrm{~g} / \mathrm{L} 2,3-\mathrm{BDO}$ by fed-batch fermentation by corn steep liquor [12]. Although these high performances of 2,3-BDO production are appealing,
Enterobacter and Klebsiella species (except for K. oxytoca) are categorized as Risk Group 2 (RG2) pathogens by the World Health Organization [3]. Therefore, such strains might not be desirable for large-scale production of 2,3-BDO because of their pathogenic properties. Scientists tried to reduce the virulence of these pathogenic bacteria by disrupting a virulence-related $w a b G$ gene [13] and eliminating pathogenic factors (lipopolysaccharides, polysaccharide capsules, and fimbrial adhesins) [14]. Although their virulence factor was dramatically reduced, however, the concentration of 2,3-BDO was unfortunately decreased by $30 \%$ [13].

Instead of using a potentially pathogenic bacterial species, we suggest using Saccharomyces cerevisiae, a species listed as Generally Recognized As Safe (GRAS), to produce 2,3-BDO. It has been reported that engineered strains of $S$. cerevisiae rapidly and efficiently utilize various sugar sources, such as xylose [15], galactose [16], cellobiose [17] and hydrolysates from cassava [18], lignocellulose [19], and red algae [20]. Moreover, as industrial polyploid strains of $S$. cerevisiae exhibit high tolerance against alcohols, sugars, and harsh fermentation conditions $[19,21,22]$, the $2,3-\mathrm{BDO}$ production process would be improved if the polyploid S. cerevisiae is used. Nonetheless, genetic manipulation of polyploid S. cerevisiae has been limited, and thus, few attempts to metabolic engineering have been made for large-scale fermentation.

Normally, ethanol production dominates in S. cerevisiae sugar metabolism. This ethanol biosynthetic pathway needs to be metabolically replaced with a 2,3-BDO-producing pathway to produce 2,3-BDO efficiently (Fig. 1). As such, the previous research of our group made three perturbations to the laboratorial haploid S. cerevisiae genome to produce 2,3-BDO instead of ethanol from sugars. First, we deleted all three pyruvate decarboxylase isozymes $(P D C 1,5,6)$, that convert pyruvate into acetaldehyde (the precursor of ethanol). Second, we introduced an enantiopure 2,3-BDO biosynthesis pathway including $\alpha$-acetolactate synthase $(a l s S)$ and $\alpha$-acetolactate decarboxylase (alsD) from Bacillus subtilis. Third, endogenous 2,3-butanediol dehydrogenase (BDH1) was over-expressed by a strong promoter of TDH3 [23]. Although the resulting Pdc-deficient haploid S. cerevisiae strain produced 2,3-BDO as a major fermentation product without ethanol production, however, the engineered strain grew slowly on glucose medium $[24,25]$. The impaired growth in the Pdc-deficient haploid strain resulted from the depletion, or limited synthesis of cytosolic acetyl-CoA which is produced from acetaldehyde via acetate [26]. To resolve the growth defect caused by the limited supply of cytosolic acetyl-CoA, the heterologous gene PDC1 from Candida tropicalis was additionally expressed in the Pdc-deficient haploid S. cerevisiae, 


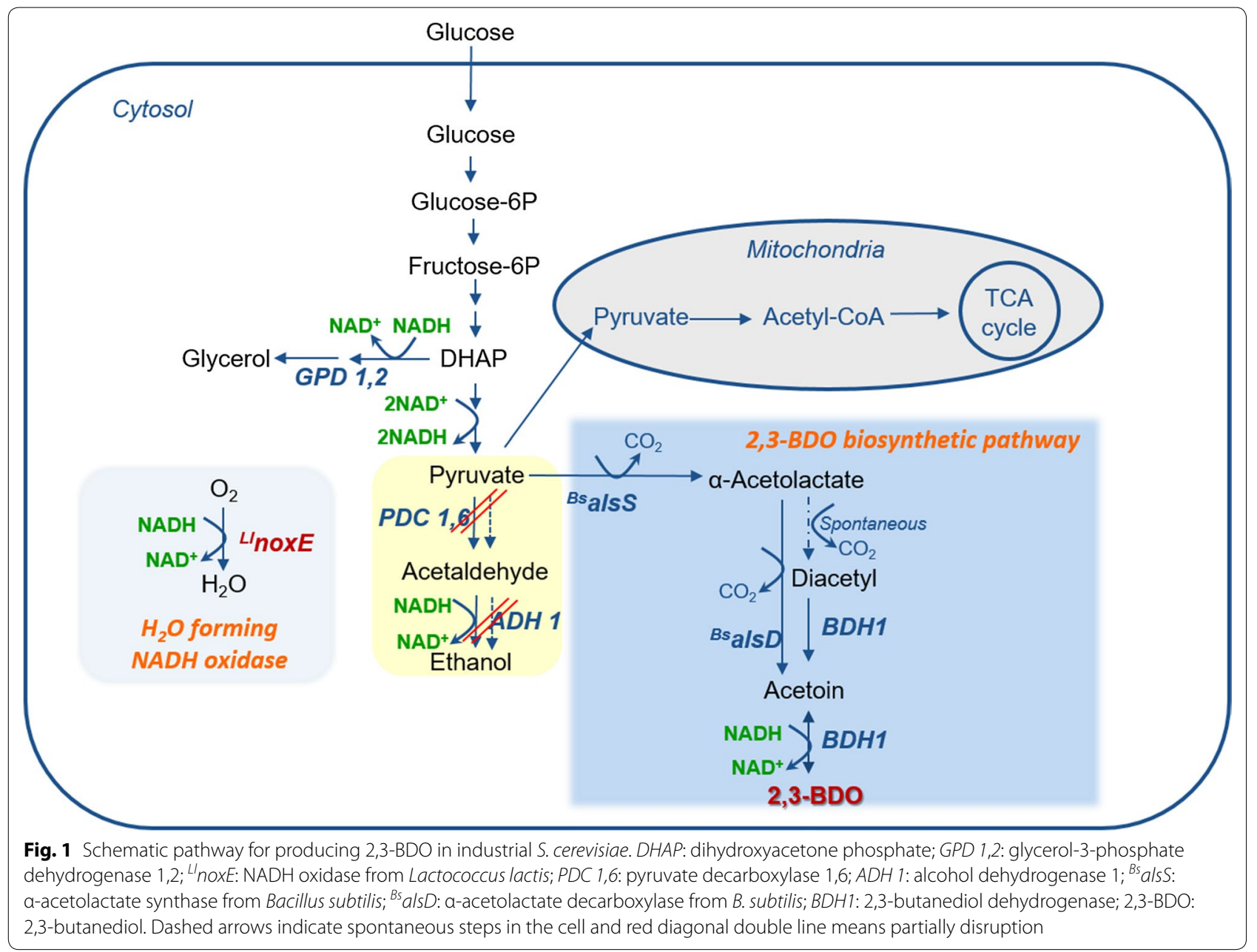

and the resulting strain produced $154.3 \mathrm{~g} / \mathrm{L} \mathrm{2,3-BDO}$. However, cell growth of pre-culture was still retarded without an ample supply of $\mathrm{C}_{2}$ compound [27]. In another study, the alcohol dehydrogenase $(A D H)$ instead of $P D C$ was deleted to address the limited production of Acetyl-CoA. However, an accumulation of acetaldehyde in this Adh-deficient $S$. cerevisiae inhibited cell growth, as well [28]. Thus, industrial-scale production of 2,3$\mathrm{BDO}$ requires adjustment to these pdc- or adh-deficient S. cerevisiae strains.

We used an industrial polyploid S. cerevisiae obtained from the process of Korean liquor fermentation. It had been adapted to the severe environment and exhibited a rapid cell growth, a high sugar consumption rate, and a high tolerance to harsh conditions [19]. With these advantages for industrial large-scale production, in this study, the industrial S. cerevisiae was metabolically engineered to produce 2,3-BDO from glucose and cassava hydrolysates. To minimize production of ethanol as a dominant metabolite of $S$. cerevisiae, we attempted to disrupt simultaneously major isozymes of $P D C$ and $A D H$ gene without decreasing cell growth on glucose as a sole carbon source. In addition, we introduced the 2,3-BDO biosynthesis pathway consisting of an endogenous $B D H 1$ and alsS and alsD from B. subtilis. The noxE gene from Lactococcus lactis was coexpressed to maintain redox balance under reduced ethanol production. In addition to the genetic perturbations, fed-batch fermentations were optimized to improve 2,3-BDO productivity. Cultivating an engineered industrial polyploid S. cerevisiae strain capable of producing 2,3-BDO in combination with optimization of the fed-batch fermentation will allow economic and environmental-friendly production of 2,3$\mathrm{BDO}$ from renewable biomass.

\section{Results}

Construction of a non-ethanologenic polyploid $S$. cerevisiae

Disruption of pyruvate decarboxylase (PDC)

The industrial polyploid S. cerevisiae (JHS200) was genetically manipulated using Cas9-based genome editing for the disruption of $P D C$ as described previously [19]. A 
Table 1 Strains and plasmids used in this study

\begin{tabular}{|c|c|c|}
\hline Strains & Genotype & Reference \\
\hline 4-JHS200 & $\mathrm{JHS} 200$, ura3 $\triangle \operatorname{trp} 1 \Delta$ his $3 \Delta$ leu2 $\Delta$ & {$[19]$} \\
\hline $4-P D C 1 d$ & 4-JHS200, pdc1 $\triangle$ & In this study \\
\hline $4-P D C 5 d$ & 4-JHS200, pdc5 $\triangle$ & In this study \\
\hline $4-P D C 6 d$ & 4-JHS200, pdc6 & In this study \\
\hline 4-PDC16d & 4-JHS200, pdc1 $\Delta p d c 6 \Delta$ & In this study \\
\hline $4-P D C 56 d$ & 4-JHS200, pdc5 $\Delta$ pdc6 $\triangle$ & In this study \\
\hline YG01 & 4-PDC16d, $\triangle a d h 1:: T D H 3_{\text {prom }}-L \operatorname{lnox}-C Y C 1_{\text {term }}$ & In this study \\
\hline YG01_SDB & YG01,p413_SDB & In this study \\
\hline YG01_SDBN & YG01, p413_SDB, p426TDH3_LInox & In this study \\
\hline YG02 & 4-PDC56d, $\triangle a d h 1:: T D H 3_{\text {prom }}-L \operatorname{lnox}-C Y C 1_{\text {term }}$ & In this study \\
\hline YG02_SDB & YG02,p413_SDB & In this study \\
\hline Plasmids & Description & Reference \\
\hline Cas9_Aur & p414-TEF1p-Cas9-CYC1t, modified Cas9 expression plasmid & [19] \\
\hline $\mathrm{pRS} 42 \mathrm{H}$ & Backbone plasmid for constructing guideRNA plasmids & {$[40]$} \\
\hline gRNA_dPDC1 & pRS42H harboring PDC1 disruption gRNA cassette & In this study \\
\hline gRNA_dPDC5 & pRS42H harboring PDC5 disruption gRNA cassette & In this study \\
\hline gRNA_dPDC6 & pRS42H harboring PDC6 disruption gRNA cassette & In this study \\
\hline gRNA_dADH1 & pRS42H harboring ADH1 disruption gRNA cassette & In this study \\
\hline p413_SDB & 2,3-BDO biosynthesis pathway (plasmid p413 harboring alsS, alsD, BDH1) & {$[28]$} \\
\hline p426TDH3_LInox & $\begin{array}{l}\text { p426TDH3 harboring noxE gene from L. lactis and template of NADH oxidase expression cas- } \\
\text { sette } \\
\text { TDH3p-LInox-CYC1t }\end{array}$ & {$[32]$} \\
\hline
\end{tabular}

termination codon (TAA) was introduced in the middle of the open reading frames (ORFs) of each $P D C$ isozymes (PDC1, PDC5, and PDC6). A quadruple auxotrophic strain (4-JHS200) [19] was used as a parental strain for the PDC disruption. First, PDC1, PDC5, and PDC6 were individually disrupted in the 4-JHS200 strain, resulting in single $P D C$-disrupted strains (4-PDC1d, 4-PDC5d, and 4-PDC6d). The fermentation performance of the single $P D C$-disrupted strains was evaluated. Compared to the parental strain (4-JHS200), there was no difference in glucose consumption rate and production of ethanol and glycerol for three different $P D C$-disrupted strains (4-PDC1d, 4-PDC5d, and 4-PDC6d) (Additional file 1: Figure S1). According to a previous report, two leftover $P D C$ genes provide enough Pdc activity for the cell growth even if one of the $P D C$ isozymes was deleted [29]. Second, the 4-PDC1d and 4-PDC5d strains were subjected to additional disruption of PDC6 using the same method. These resulting strains of 4-PDC16d and 4-PDC56d (Table 1) were cultured in YP medium with $50 \mathrm{~g} / \mathrm{L}$ of glucose to evaluate the effects of double disruption of $P D C$ genes. As the 4-PDC16d strain has only PDC5 and the 4-PDC56d strain has only PDC1, we reasoned the partial disruption of $P D C$ genes might maintain cell growth rate even without the supplement of $\mathrm{C}_{2}$-compounds. As previously reported, complete deficiency of Pdc activity in S. cerevisiae causes severe growth defects on glucose, and requires $C_{2}$ compounds such as ethanol and acetic acid for growth $[25,27,29]$. As shown in the fermentation results (Additional file 1: Figure S1), the 4-PDC16d and 4-PDC56d strains produced ethanol and glycerol slightly less than the control strain (4-JHS200). Based on the amount of ethanol produced, we speculated that the 4-PDC16d strain might have a lower Pdc activity than the 4-PDC56d strain or the control strain. To confirm, we measured the Pdc activities of the $P D C$-disrupted strains. The double $P D C$-disrupted strains (4-PDC16d and 4-PDC56d) showed decreased Pdc activities as compared to the single $P D C$-disrupted strains (4-PDC1d, 4-PDC5d, and 4-PDC6d) (Fig. 2). The single $P D C$-disrupted strains maintained Pdc activity at a similar or slightly lower level compared with the control strain (4-JHS200), and the 4-PDC16d strain exhibited the lowest Pdc activity (Fig. 2). Thus, the 4-PDC16d strain with the attenuated Pdc activity was viewed as beneficial as a platform strain to produce 2,3-BDO instead of ethanol from pyruvate.

\section{Deletion of alcohol dehydrogenase (ADH) with chromosomal expression of NADH oxidase (noxE)}

In addition to $P D C$ disruption, the expression levels of alcohol dehydrogenases $(A D H)$, which convert 


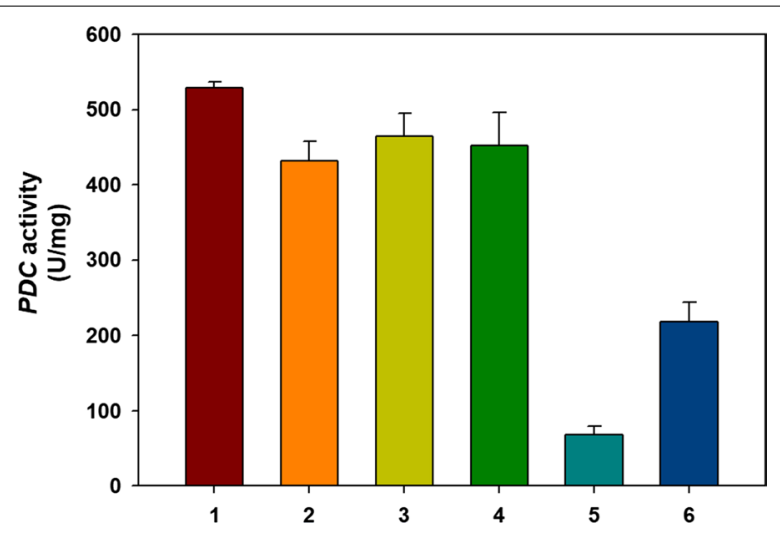

Fig. $\mathbf{2}$ In vitro activity assay of endogenous PDC in engineered S. cerevisiae strains. Assays were replicated by four independent experiments. 1: 4-JHS2O0 (the control host strain); 2: 4-PDC1d (only PDC1 disrupted); 3: 4-PDC5d (only PDC5 disrupted); 4: 4-PDC6d (only PDC6 disrupted); 5: 4-PDC16d (PDC1 and PDC6 disrupted); 6 : 4-PDC56d (PDC5 and PDC6 disrupted)

acetaldehyde to ethanol (Fig. 1), can be modulated to reduce ethanol production. It has been known that there are five isozymes $(A D H 1-A D H 5)$ of alcohol dehydrogenase in S. cerevisiae. However, similar to the Pdcdeficient strain, the Adh-deficient strain also had fatal features, such as an intracellular redox imbalance and deficient cell growth caused by accumulation of acetaldehyde $[30,31]$. Therefore, $A D H 1$ known as the major active enzyme out of the five isozymes would be deleted for reducing ethanol production [30]. Since deletion of the NADH-dependent $A D H 1$ gene might cause cofactor imbalance, the heterologous water-forming NADH oxidase (noxE) from L. lactis was simultaneously introduced in the middle of $A D H 1$ chromosome. An expression cassette (including $T D H 3$ promoter and $C Y C 1$ terminator) of NADH oxidase was amplified from the plasmid of p426TDH_Llnox (Table 1). This expression cassette of NADH oxidase (noxE) was introduced into the middle of the $A D H 1$ chromosome in the 4-PDC16d and 4-PDC56d strains, resulting in the deletion of $A D H 1$ with expression of noxE. The resulting strains were named as YG01 (4-PDC16dADH1d) and YG02 (4-PDC56dADH1d), respectively. The YG01 strain has intact $P D C 5$ and deleted $A D H 1$ by the chromosomally expression of noxE, and the YG02 strain has intact $P D C 1$ and deficient $A D H 1$ by noxE expression.

These two resulting strains were cultured in YP medium with $40 \mathrm{~g} / \mathrm{L}$ glucose. Both YG01 and YG02 strains did not grow well, but produced a small amount of ethanol $(<2 \mathrm{~g} / \mathrm{L})$ (Additional file 1: Figures S2, S3). If the YG01 and YG02 strains lost their Adh activity by expression of noxE in the middle of the $A D H 1$ chromosome, acetaldehyde would not be converted to ethanol and accumulated in the cell (Fig. 1). In fact, we detected that $55 \mathrm{mg} / \mathrm{L}$ of acetaldehyde accumulated in the YG01 and YG02 cells, which was a 100-fold higher than that in the control strain (4-PDC16d) (data not shown). The accumulated acetaldehyde could not be converted to ethanol due to the weakened Adh activity in the YG01 and YG02 strains.

\section{Introduction of a 2,3-BDO pathway} to the non-ethanologenic yeast strains

The next step was to introduce a 2,3-BDO biosynthetic pathway consisting of alsS and alsD from $B$. subtilis and over-expression of endogenous $B D H 1$ in the nonethanologenic strains, YG01 and YG02. Specifically, the plasmid p413_SDB containing alsS, alsD, and BDH1 under strong promoters was introduced into the YG01 and YG02 strains. Thus, carbon fluxes from pyruvate were redirected into $\alpha$-acetolactate using $\alpha$-acetolactate synthase encoded by alsS. Then, $\alpha$-acetolactate was converted into acetoin via $\alpha$-acetolactate decarboxylase encoded by als $D$. The butanediol dehydrogenase enzyme encoded by $B D H 1$ converted acetoin into 2,3-BDO. The resulting strains were named as YG01_SDB and YG02 SDB (Table 1).

To evaluate fermentation performance changes after introducing the 2,3-BDO biosynthetic pathway, the YG01_SDB and YG02_SDB strains were cultured in a flask containing YP medium with $50 \mathrm{~g} / \mathrm{L}$ of glucose. As shown in Fig. 3, the YG01_SDB strain was found to be more suitable for the production of 2,3-BDO than the YG02_SDB strain. The glucose consumption rate of the YG01_SDB strain was faster than that of the YG02_SDB strain. As a result, the cell concentration of the YG01_SDB strain reached a maximum faster than the YG02_SDB strain (Fig. 3a, b). Moreover, the YG02 SDB produced a small amount of ethanol $(<2 \mathrm{~g} / \mathrm{L})$ during the fermentation. Therefore, the YG02_SDB strain was excluded for further experiments. As summarized in Table 2, the YG01_SDB strain produced $14.9 \mathrm{~g} / \mathrm{L}$ of 2,3-BDO from $50 \mathrm{~g} / \mathrm{L}$ glucose within $20 \mathrm{~h}$. Although a substantial amount $(9.56 \mathrm{~g} / \mathrm{L})$ of glycerol accumulated, the YG01_SDB yielded $0.295 \mathrm{~g} 2,3-\mathrm{BDO} / \mathrm{g}$ glucose at a rate of $0.745 \mathrm{~g} / \mathrm{L} \mathrm{h}$ in a flask fermentation. After $20 \mathrm{~h}$, the 2,3-BDO product was gradually converted into acetoin. Once glucose was depleted, it was likely the lack of $\mathrm{NADH}$ affected the cell growth. As such, acetoin accumulated from the oxidation of 2,3-BDO into acetoin for regenerating $\mathrm{NADH}$. As the total amount of 2,3-BDO and acetoin remained unchanged, we speculated that acetoin was not metabolized further for respiratory growth [28]. 

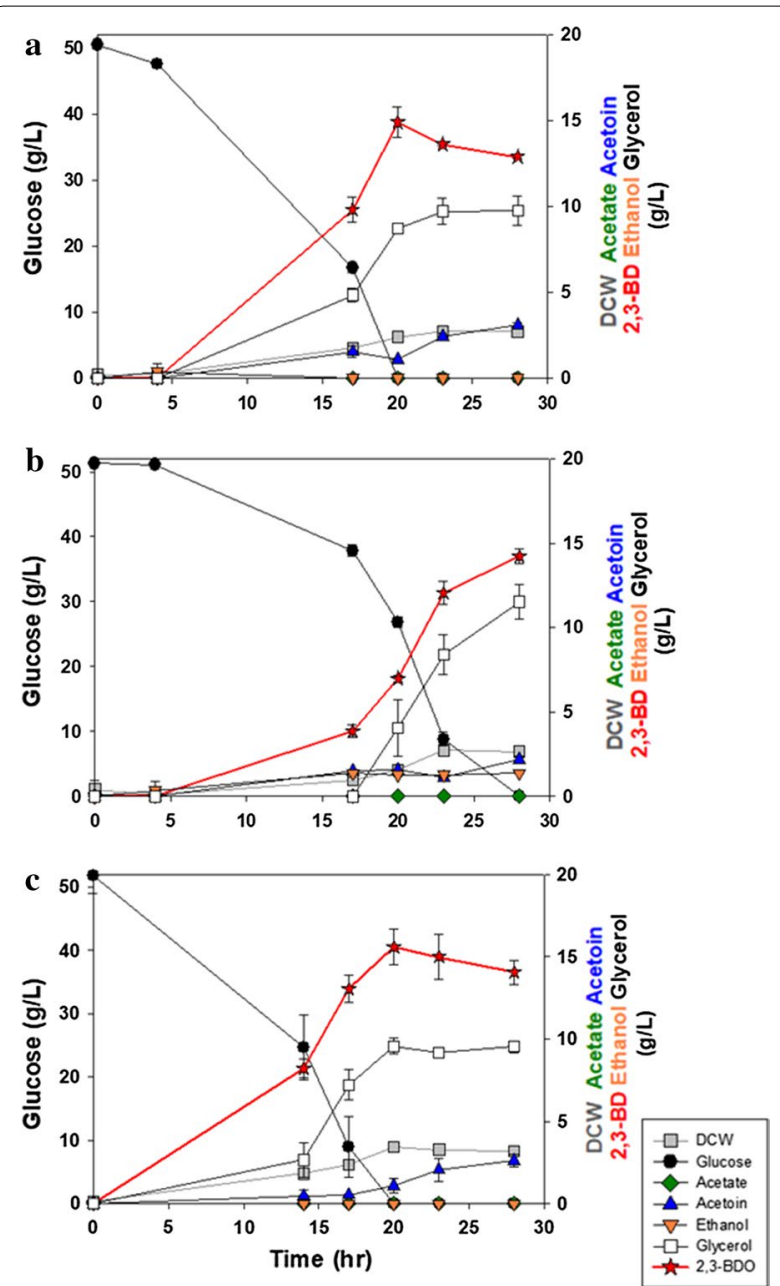

Fig. 3 Flask fermentation of a YG01_SDB, b YG02_SDB, and $\mathbf{c}$ YG01_ SDBN strains with $50 \mathrm{~g} / \mathrm{L}$ glucose in YP medium. Error bars indicate standard deviations of three independent experiments

\section{Relieve of cellular redox imbalance by over-expressed NADH oxidase}

Typically, alcohol dehydrogenase converts two molecules of acetaldehyde into two moles of ethanol with consumption of two moles of NADH (Fig. 1). Therefore, deleting the $A D H 1$ gene caused an accumulation of $\mathrm{NADH}$ in the cytosol of the non-ethanologenic strain (YG01). The surplus NADH produced during 2,3-BDO biosynthesis usually could be reoxidized into $\mathrm{NAD}^{+}$via the glycerol overproduced [28]. However, the accumulation of glycerol obstructs the efficient production of 2,3-BDO as substantial amounts of a carbon source can be wastefully incorporated into glycerol. In addition, downstream processing will be complicated due to the similar chemical properties between glycerol and 2,3-BDO. To reduce the accumulation of glycerol, surplus NADH can be efficiently oxidized into $\mathrm{NAD}^{+}$using a water-forming NADH oxidase from L. lactis [32]. When the $A D H 1$ gene was deleted, an expression cassette of noxE was inserted into the $A D H 1$ gene site in the chromosome of the YG01_ SDB strain. However, the chromosomal single copy-number-based expression was not sufficient to compete for NADH with GPD (glycerol-3-phosphate dehydrogenase), resulting in accumulation of glycerol during 2,3-BDO biosynthesis (Fig. 3a). Therefore, a multi-copy-number plasmid (p426TDH3_Llnox) was introduced into the YG01_SDB strain for enhancement of NADH oxidase activity. The resulting strain (YG01_SDBN) indicated a lower glycerol yield than the parental strain (YG01_SDB) (Fig. 3b, c). As expected, the NADH oxidase expression levels were inversely proportional to the glycerol accumulation levels, and proportional to 2,3-BDO production (Table 2). While the YG01_SDBN produced glycerol, we reasoned it is because of limited supply of oxygen in a flask fermentation.

To maintain the oxygen level, a fed-batch fermentation was conducted in a $1 \mathrm{~L}$ fermentor with the YG01_SDBN (Fig. 4). After the initially added glucose (100 g/L) was depleted, $800 \mathrm{~g} / \mathrm{L}$ glucose-concentrated solution was intermittently fed when glucose concentration decreased to $20 \mathrm{~g} / \mathrm{L}$ or less during the fermentation. Aeration conditions were controlled at $400 \mathrm{rpm}$ and a flow rate of $2 \mathrm{vvm}$. The dissolved oxygen level in the medium was kept below $2.0 \%$. The fed-batch fermentation showed two phases of 2,3-BDO production (Fig. 4). For the first $49 \mathrm{~h}$ of fermentation, the YG01_SDBN strain could produce high concentrations of 2,3-BDO $(129 \mathrm{~g} / \mathrm{L})$ with a high rate of $2.64 \mathrm{~g} / \mathrm{L} \mathrm{h}$, which is comparable to the fermentation performances of bacteria-based processes. After $49 \mathrm{~h}$ of fermentation, 2,3-BDO production increased to $178 \mathrm{~g} / \mathrm{L}$, at

Table 2 Summary of the flask culture with the engineered industrial yeast strains

\begin{tabular}{lllllll}
\hline Strains & Products (g/L) & & & & $\begin{array}{l}\text { Yield of 2,3-BDO (g 2,3- } \\
\text { BDO/g glucose) }\end{array}$ & $\begin{array}{l}\text { Productivity } \\
\text { of 2,3-BDO } \\
\text { (g/L h) }\end{array}$ \\
\cline { 2 - 7 } & DCW & $\mathbf{2 , 3 - B D O}$ & Glycerol & Acetoin & Ethanol & 0.745 \\
\hline YG01_SDB & 2.72 & 14.9 & 9.56 & 3.11 & N/D & 0.295 \\
YG02_SDB & 2.65 & 14.2 & 9.97 & 2.20 & 1.37 & 0.277 \\
YG01_SDBN & 3.19 & 15.6 & 9.78 & 2.62 & N/D & 0.301 \\
\hline
\end{tabular}

$N / D$ not detected 


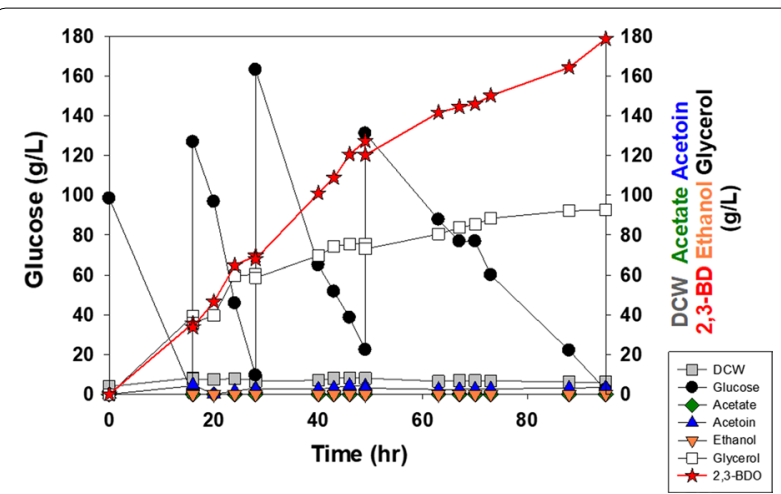

Fig. 4 Fed-batch fermentation of YG01_SDBN strain in a fermentor with YP medium

the expense of overall productivity, which declined from 2.64 to $1.88 \mathrm{~g} / \mathrm{L}$ h, probably because of high osmotic pressure caused by high concentrations of 2,3-BDO (Table 3). No ethanol production was observed in the fed-batch fermentation. With these fermentation results, the metabolically engineered industrial polyploid $S$. cerevisiae strain (YG01_SDBN) constructed in this work has successfully demonstrated the possibility of producing high concentration of 2,3-BDO with high productivity.

\section{Production of 2,3-BDO from a cassava hydrolysate}

To be competitive with chemical synthesis of 2,3-BDO, a microbial fermentation process should produce 2,3BDO efficiently from inexpensive substrates. As shown in previous studies, the same parental strain (JHS200), such as the engineered polyploid $S$. cerevisiae strain used in this study, has outstanding examples of fermenting a cellulosic hydrolysate containing substantial amounts of fermentation inhibitors [19]. Therefore, we evaluated the production of 2,3-BDO by the YG01_SDBN strain with a cassava hydrolysate. The batch culture of a cassava hydrolysate was carried out using the YG01_SDBN strain in a $1 \mathrm{~L}$ scale fermentor (Fig. 5a). The cassava hydrolysates

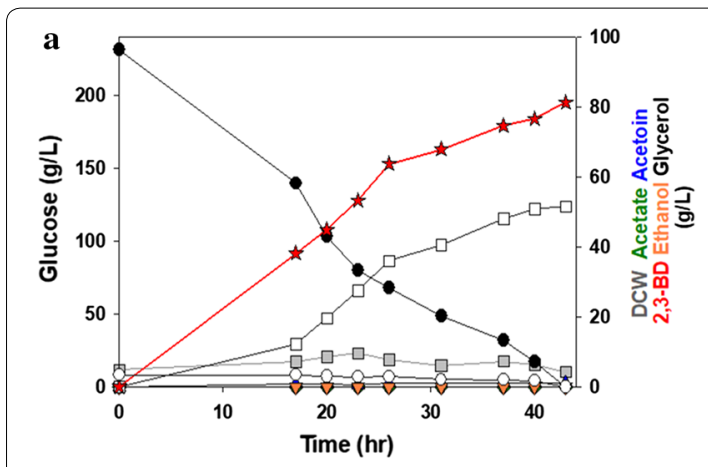

b

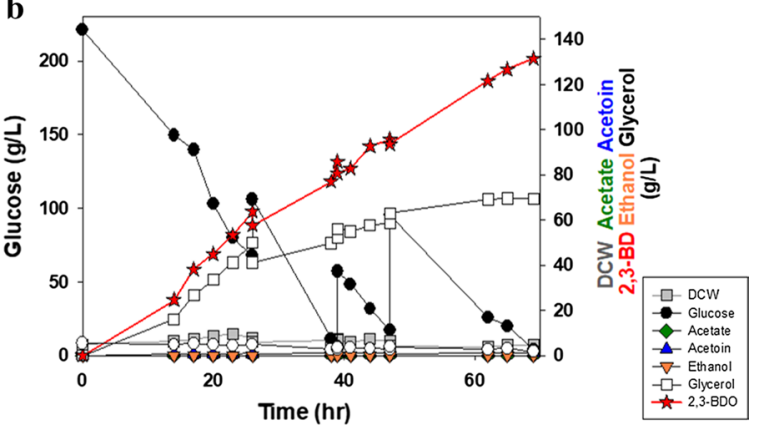

Fig. 5 Fermentation of YG01_SDBN strain in a fermentor with a cassava hydrolysate. $\mathbf{a}$ Batch and $\mathbf{b}$ fed-batch fermentation

contained $266 \mathrm{~g} / \mathrm{L}$ of glucose as a carbon source, and $10 \mathrm{~g} / \mathrm{L}$ of yeast extract and $20 \mathrm{~g} / \mathrm{L}$ of peptone were added as a nitrogen source. During $43 \mathrm{~h}$ of the batch fermentation, 81.2 $\mathrm{g} / \mathrm{L} 2,3-\mathrm{BDO}$ was produced with a productivity of $1.89 \mathrm{~g} / \mathrm{L} \mathrm{h}$ and a yield of $0.305 \mathrm{~g}$ 2,3-BDO/g glucose (Table 3). These results are comparable to rates of bacterial fermentations of hydrolysates [33].

A fed-batch fermentation using the cassava hydrolysate was also performed under the same conditions of aeration and feeding strategies as done in the YP mediumbased fermentation. The fed-batch fermentation of the cassava hydrolysate with the YG01_SDBN strain produced $132 \mathrm{~g} / \mathrm{L}$ of 2,3-BDO within $69 \mathrm{~h}$ with a productivity

Table 3 Summary of fermentations with the YG01_SDBN strain in a fermentor

\begin{tabular}{|c|c|c|c|c|c|c|c|c|}
\hline \multicolumn{4}{|l|}{ Fed-batch fermentation with YP medium } & \multicolumn{2}{|c|}{ Up to $49 \mathrm{~h}$} & \multicolumn{3}{|c|}{ Overall } \\
\hline Concentration of 2,3-BDO (g/L) & & & & 129 & & & 178 & \\
\hline Yield of 2,3-BDO (g 2,3-BDO/g glucose) & & & & 0.313 & & & 0.335 & \\
\hline Productivity of 2,3-BDO (g/L h) & & & & 2.64 & & & 1.88 & \\
\hline \multirow[t]{2}{*}{ Fermentation with cassava hydrolysates } & \multicolumn{5}{|c|}{ Products (g/L) } & \multirow{2}{*}{\multicolumn{2}{|c|}{$\begin{array}{l}\text { Yield of 2,3-BDO ( } \mathrm{g} \\
2,3-\mathrm{BDO} / \mathrm{g} \text { glucose) }\end{array}$}} & \multirow{2}{*}{$\begin{array}{l}\text { Productivity } \\
\text { of 2,3-BDO } \\
(\mathrm{g} / \mathrm{L} \mathrm{h})\end{array}$} \\
\hline & $\mathrm{DCW}$ & 2,3-BDO & Glycerol & Acetoin & Ethanol & & & \\
\hline Batch & 9.55 & 81.2 & 51.5 & 1.17 & N/D & 0.305 & & 1.89 \\
\hline Fed-batch & 8.45 & 132 & 69.4 & 1.19 & $N / D$ & 0.324 & & 1.92 \\
\hline
\end{tabular}

ND not detected 
of $1.92 \mathrm{~g} / \mathrm{L} \mathrm{h}$ (Fig. $5 \mathrm{~b}$ ). While the production of 2,3-BDO continued to increase at a constant rate, the amount of glycerol reduced, so the 2,3-BDO yield $(0.324 \mathrm{~g} 2,3-$ $\mathrm{BDO} / \mathrm{g}$ glucose) was greater than the yield of the batch fermentation (0.305 g 2,3-BDO/g glucose). Although the cassava hydrolysate contained a high concentration of glucose, the YG01_SDBN strain was able to produce 2,3-BDO with a better yield and productivity from the cassava hydrolysate than from YP medium with glucose. Cassava has been known as an accessible substrate in tropical regions such as Southeast Asia and Africa, and its hydrolysate could be a good biomass [34]. With this aspect, this constructed industrial polyploid $S$. cerevisiae strain can be employed to produce 2,3-BDO with a high productivity using inexpensive substrates such as a cassava hydrolysate.

\section{Discussion}

This study aimed that the microbial production of 2,3BDO would be improved by an industrial polyploid $S$. cerevisiae with high titer and productivity. As the industrial yeast strain has fast growth rate, sugar metabolism, and resistance to fermentation inhibitors, it is suitable for the large-scale fermentation with a biomass hydrolysate in industrial fields [19]. Furthermore, if genetic modification is successfully carried out in an industrial polyploid $S$. cerevisiae without some problems shown in previous studies, the engineered polyploid strain can produce high titer of 2,3-BDO with high productivity as much as engineered bacteria. Although some bacteria species are native producers of 2,3-BDO, most of them are classified into the Risk Group 2, which contains pathogenic organisms unsuitable for the large-scale fermentation. Possibility of fatal infection by bacteriophage should also be resolved in bacterial production of 2,3-BDO [35]. As such, the improved 2,3-BDO biosynthesis of the industrial polyploid $S$. cerevisiae could be feasible in the production of 2,3-BDO from renewable biomass. Though a polyploid $S$. cerevisiae has various advantages for largescale fermentation process, its genetic manipulation has been limited [36]. The CRISPR-Cas9 genome-editing technology could be applicable to manipulating the genome of industrial polyploid yeast in this study.

We hypothesized that an expression level of the pyruvate decarboxylase $(P D C)$ and alcohol dehydrogenase $(A D H)$ genes could be modulated to construct a nonethanologenic strain capable of growing on glucose as a sole carbon source without supplementation of a $\mathrm{C}_{2}$-compound. Using an industrial polyploid $S$. cerevisiae as a parental strain, partial disruption of $P D C$ isozymes was combined with partially deleted $A D H$ isozymes to minimize ethanol production from glucose as a sole carbon source without growth inhibition. Among the three isozymes $(P D C 1,5,6)$ of pyruvate decarboxylase, the combination of disrupted PDC1 and PDC6 was exhibited the lowest activity of $P D C$ (Fig. 2). This partial disruption of $P D C$ isozymes had solved the problems of $\mathrm{C}_{2}$-auxotrophy and growth inhibition, which typically occurred in Pdc-deficient laboratorial haploid yeast strains $[24,27]$. There has been reported chromosomal instability, however, caused by incomplete deletion of genes in polyploid S. cerevisiae. To confirm the stability of genetic modifications, we investigated the genome sequence by DNA sequencing. As shown in Additional file 1: Figure S4, genetic manipulation of inserting the stop codon (TAA) has been maintained from the first transformants (left side) to the 60th generations strain (right side).

Furthermore, by eliminating only the Adh1 activity among the six isozymes of $A D H$, ethanol biosynthesis could be minimized without a severe metabolic burden. As a result, a non-ethanologenic polyploid S. cerevisiae (YG01) could not produce ethanol at all and was barely able to grow. Partial disruption of $P D C$ and $A D H$ isozymes blocked the metabolic pathway from pyruvate to ethanol, resulting in the accumulation of acetaldehyde $(55 \mathrm{mg} / \mathrm{L})$ in the cells, which prohibited cell growth (Additional file 1: Figures S2, S3). The introduction of the 2,3-BDO biosynthetic pathway allowed the massive shift of carbon flux from pyruvate to 2,3-BDO. Since the $\mathrm{NADH}$ oxidase had been introduced at the $A D H 1$ chromosome site in the process of $A D H 1$ disruption, the level of NADH expression could be an indicator measured to confirm the disruption of $A D H 1$ and chromosomal expression of noxE. To determine the expression level of the noxE gene, the NADH oxidase activity was measured for the YG01_SDB and YG02_SDB. As mentioned above, the YG01 and YG02 strains struggled to grow, so NADH oxidase activity was measured in the YG01_SDB and YG02_SDB strains. These strains were genetically identical to YG01 and YG02 except for additional introduction of the 2,3-BDO pathway. The chromosomally noxE expressed strains (YG01_SDB and YG02_SDB) showed higher activity than the control strain (4-JHS200), indicating the confirmation of the successfully introduced heterologous noxE gene (Fig. 6). In conclusion, the nonethanologenic polyploid S. cerevisiae strains (YG01 and YG02), which were constructed by partially disrupting $P D C$ and $A D H$ by introduction of the heterologous noxE gene, are a promising platform to biosynthesize various products from pyruvate.

Based on the glycerol production yield of YG01_SDBN and YG01_SDB strain, over-expression of NADH oxidase relieved the redox imbalance caused by blocking the ethanol biosynthetic pathway which oxidized cellular NADH. Production of glycerol which oxidizes excessive NADH 

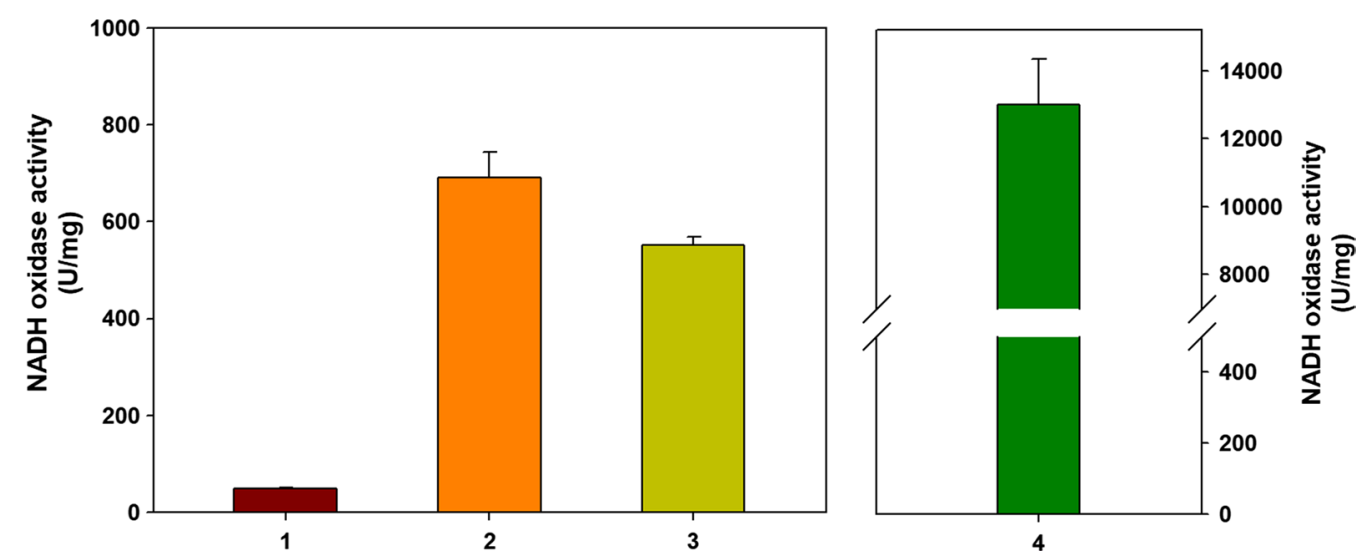

Fig. 6 In vitro activity assay of heterologous NADH oxidase expressed in engineered S. cerevisiae strains. Assays were replicated by four independent experiments. 1: 4-JHS200 (the parental strain); 2: YG01_SDB (partially disrupted PDC1, PDC6, and ADH1 genes with the chromosomal expression of noxE gene and introduced 2,3-BDO pathway); 3: YG02_SDB (partially disrupted PDC5, $P D C 6$, and ADH1 genes with the chromosomal expression of noxE gene and introduced 2,3-BDO pathway); 4:YG01_SDBN (partially disrupted PDC1, PDC6, and ADH1 genes with the chromosomal expression of noxE gene, introduced 2,3-BDO pathway and expressed with the plasmid of p426TDH3_LInox)

into $\mathrm{NAD}^{+}$in the cell, however, inevitably occurred in the process of 2,3-BDO biosynthesis. Thus, a water-forming $\mathrm{NADH}$ oxidase was introduced to alleviate the intracellular imbalance in the NADH/NAD ${ }^{+}$ratio and to reduce the glycerol accumulation [27]. Under the optimized fermentation conditions, the resulting engineered industrial strain (YG01_SDBN) produced $178 \mathrm{~g} / \mathrm{L}$ 2,3-BDO with a maximum productivity of $2.64 \mathrm{~g} / \mathrm{L} \mathrm{h}$ in a fed-batch fermentation using glucose-based YP medium.

For a cassava hydrolysate, the YG01_SDBN strain could also produce 2,3-BDO while maintaining its advantageous properties such as tolerance to sugars and fermentation inhibitors at high concentrations, and rapid sugar consumption rates. This strain under fed-batch conditions using a cassava hydrolysate produced $132 \mathrm{~g} / \mathrm{L}$ of 2,3-BDO with a yield of $0.324 \mathrm{~g} 2,3-\mathrm{BDO} / \mathrm{g}$ glucose. These results demonstrate that an engineered industrial polyploid S. cerevisiae might serve as a technical platform to produce valuable chemicals from inexpensive hydrolysates of renewable biomass.

\section{Conclusions}

In this study, we introduced the 2,3-BDO biosynthesis system (alsS, alsD from $B$. subtilis with over-expressed endogenous $B D H 1$ ) into an industrial polyploid $S$. cerevisiae and produced 2,3-BDO very efficiently. Unlike previous studies [24,27,28], the combination of disrupted $P D C 1 / P D C 6$ and $A D H 1$ rerouted carbon fluxes into the 2,3-BDO biosynthesis pathway instead of into ethanol production and avoided any severe growth defects. We successfully developed an engineered industrial polyploid S. cerevisiae strain (YG01_SDB and YG02_SDB) able to overcome $\mathrm{C}_{2}$-dependent growth and display various advantages among industrial strains when producing 2,3-BDO. In addition, the concentration of 2,3BDO $(178 \mathrm{~g} / \mathrm{L})$ by the engineered polyploid S. cerevisiae strain (YG01_SDBN) is one of the highest titer reported for microbial production of 2,3-BDO. While microbial production of 2,3-BDO has been studied in various species of microorganism and various ways [37], attempts in an industrial polyploid S. cerevisiae are novel [38]. Besides, the results of cassava hydrolysate fermentation using the engineered polyploid S. cerevisiae are not inferior even compared with those of bacteria including $K$. oxytoca [39]. We expect that an engineered polyploid S. cerevisiae could be a powerful platform strain for production of biofuels and biochemicals with environmental and economic benefits.

\section{Methods}

\section{Strains and culture media}

Escherichia coli Top 10 (Invitrogen, Carlsbad, CA, USA) was used for plasmid construction and gene manipulation. We grew the E. coli transformants in Lysogeny Broth (LB) medium with $100 \mu \mathrm{g} / \mathrm{mL}$ ampicillin. The industrial S. cerevisiae strain used in this study was found to be polyploid. The engineered polyploid 4-JHS200 was described in a previous study [19]. We cultivated the yeast strains in YP $(10 \mathrm{~g} / \mathrm{L}$ yeast extract and $20 \mathrm{~g} / \mathrm{L}$ peptone) medium with $0.5 \mu \mathrm{g} / \mathrm{mL}$ aureobasidin A (Takara, Shiga, Japan) or $300 \mu \mathrm{g} / \mathrm{mL}$ hygromycin B (SigmaAldrich, St. Louis, MO, USA). Some of the engineered industrial strains were selected on YNB medium $(6.7 \mathrm{~g} / \mathrm{L}$ yeast nitrogen base, proper nucleotides and amino acids) with $0.5 \mu \mathrm{g} / \mathrm{mL}$ aureobasidin A and $300 \mu \mathrm{g} / \mathrm{mL}$ hygromycin $\mathrm{B}$ as selection markers. 


\section{Construction of plasmids}

Table 1 summarizes the plasmids used in this study. Primers used to construct gBlock and repair DNA are presented in Additional file 1: Table S1. The Cas9 expression plasmid named Cas9_Aur was used [19]. Customized guide RNA-expressing plasmids were constructed as follows. First, three guide RNA-expressing cassettes with different sequences targeting $P D C 1, P D C 5$, and PDC6 were synthesized to have blunt ends for $S a c \mathrm{I}$ and $K p n \mathrm{I}$ digestion. The AccuGeneBlock service (Bioneer Co., Korea) synthesized these guide RNA cassettes (Additional file 1: Table S2). Second, the synthesized guide RNA cassettes and plasmid pRS42H [40] were digested using $S a c \mathrm{I}$ and $K p n \mathrm{I}$, and ligated to each other. Third, we obtained the guide RNA-expressing plasmids, gRNA_ dPDC1, gRNA_dPDC5, and gRNA_dPDC6 for disruption of PDC1, PDC5, and PDC6, respectively. The guide RNA-expressing plasmids for the disruption of $A D H 1$ (gRNA_dADH1) [41] and the plasmid p426TDH3_Llnox were described in a previous study [32]. The constructed 2,3-BDO pathway was introduced via plasmid p413_SDB, which was kindly donated by Prof. Ji-Sook, Hahn [28]. This plasmid p413_SDB consists of a heterogeneous alsS and alsD from $B$. subtilis and an over-expressed innate gene $B D H 1$ under the control of strong constitutive promoters $\left(\mathrm{P}_{T D H 3}, \mathrm{P}_{T E F I}\right.$, and $\mathrm{P}_{T P I I}$, respectively), and had different terminators [28].

\section{Construction of metabolically engineered S. cerevisiae by transformation}

For the construction of $P D C$-disrupted strains, 4-JHS200 harboring Cas9-Aur (Cas9-expression plasmid) was transformed with guide RNA plasmids and repair DNA fragments amplified by PCR. To introduce the 2,3-BDO biosynthetic pathway, plasmid p413_SDB was transformed into the YG01 and YG02 strains using the Spheroplast Transformation Kit (BIO 101, Vista, CA, USA). To select the transformants, S. cerevisiae strains were cultivated aerobically at $30{ }^{\circ} \mathrm{C}$ in YNB medium $(6.7 \mathrm{~g} / \mathrm{L}$ Yeast Nitrogen Base, appropriate nucleotides, and amino acids) with $20 \mathrm{~g} / \mathrm{L}$ glucose.

\section{Activity assay of NADH oxidase and pyruvate decarboxylase}

To measure NADH oxidase activity in a cell, a crude extract was prepared by growing and harvesting the mid-exponential phase cells (up to $1 \times 10^{8}$ to $10^{9}$ ) grown in YNB medium-containing $20 \mathrm{~g} / \mathrm{L}$ glucose, followed by two washes of distilled water. After adding the protease inhibitor (Roche, Basel, Switzerland), the harvested cells were lysed using the yeast protein extraction reagent (Thermo Scientific, Waltham, MA, USA).
Cells were centrifuged at $7000 \mathrm{~g}$ and $4{ }^{\circ} \mathrm{C}$ for $20 \mathrm{~min}$, and the supernatant was collected and tested for NADH oxidase activity within $3 \mathrm{~h}$. The reaction mixture contained $50 \mathrm{mM}$ potassium phosphate buffer $(\mathrm{pH} 7.0)$, $0.4 \mathrm{mM} \mathrm{NADH}$, and $0.3 \mathrm{mM}$ EDTA [42]. Enzyme activity was defined as the degree of absorbance reduction at $340 \mathrm{~nm}$. One unit is defined as the enzyme amount needed to oxidize $1 \mu \mathrm{mol}$ NADH under the conditions mentioned above for 3 min.

To measure the Pdc activity in the cells, we prepared a crude extract using the methods already described. The Pdc activity was assayed at $30{ }^{\circ} \mathrm{C}$ with a reaction mixture containing $40 \mathrm{mM}$ imidazole hydrochloride buffer $(\mathrm{pH}$ 6.5), $5 \mathrm{mM} \mathrm{MgCl}, 0.2 \mathrm{mM}$ TPP, $17 \mathrm{U}$ of alcohol dehydrogenase from S. cerevisiae, $0.4 \mathrm{mM} \mathrm{NADH}$, and $50 \mathrm{mM}$ pyruvate [43]. We initiated the reactions by adding pyruvate and measured the change in absorbance at $340 \mathrm{~nm}$. One unit of activity was defined as the amount of enzyme oxidizing $1 \mu \mathrm{mol} \mathrm{NADH}$ per minute in the corresponding reaction conditions. The protein concentration of crude extracts was also determined by the Bradford method [44].

\section{Culture conditions}

The engineered yeast strains were pre-cultured in $5 \mathrm{~mL}$ of YP medium or YNB medium-containing $20 \mathrm{~g} / \mathrm{L}$ glucose at $30{ }^{\circ} \mathrm{C}$ and $250 \mathrm{rpm}$ for $24 \mathrm{~h}$. After growth, cells were harvested and transferred to $100 \mathrm{~mL}$ of $\mathrm{YNB}$ medium-containing $20 \mathrm{~g} / \mathrm{L}$ glucose in a baffled flask at $30{ }^{\circ} \mathrm{C}$ and $250 \mathrm{rpm}$ for $24 \mathrm{~h}$. These cells at mid-exponential growth state $\left(\mathrm{OD}_{600}<3\right)$ were harvested for use as an inoculum. Main batch cultures were carried out under microaerobic conditions in $250 \mathrm{~mL}$ Erlenmeyer flasks at $30^{\circ} \mathrm{C}$ and $150 \mathrm{rpm}$. Fed-batch fermentations were done using a $1 \mathrm{~L}$ bench-top fermentor (Fermentec, Cheongju, Korea) filled with $500 \mathrm{~mL} \mathrm{YP}$ medium-containing initial $100 \mathrm{~g} / \mathrm{L}$ glucose and held at $30{ }^{\circ} \mathrm{C}$. The $\mathrm{pH}$ was targeted to 5.5 by the intermittent addition of $5 \mathrm{~N} \mathrm{NaOH}$ solution. An $\mathrm{O}_{2}$ sensor (Mettler Toledo, Greifensee, Switzerland) was used to measure the dissolved oxygen (DO). Fed-batch cultivation was done using a fermentor operated at $400 \mathrm{rpm}$ with an air flow rate of $2 \mathrm{vvm}$. During the fed-batch fermentation, DO levels were kept below $2.0 \%$. Cells prepared from the flask culture were used to inoculate the fed-batch culture at an initial concentration of $5.0 \mathrm{~g}_{\mathrm{DCW}} / \mathrm{L}$. When glucose concentration fell below $20 \mathrm{~g} / \mathrm{L}$, glucose-concentrated solution $(800 \mathrm{~g} / \mathrm{L})$ was added into the culture broth.

For the hydrolysate fermentations, $10 \mathrm{~g} / \mathrm{L}$ yeast extract and $20 \mathrm{~g} / \mathrm{L}$ peptone were added into the cassava hydrolysates from Changhae Ethanol Co., Ltd. Other fermentation conditions are the same as the above description. 


\section{Preparation of cassava hydrolysates}

Enzymatic hydrolysis can be used to obtain $100 \mathrm{~g}$ glucose from $126 \mathrm{~g}$ of the cassava chips. Using this information, cassava hydrolysates were prepared from cassava chips (starch contents equal to approximately $72 \%$ dry weight basis) imported from Vietnam. Cassava chips were ground using a hammer mill and passed through a $1 \mathrm{~mm}$ screen. For liquefaction, $0.7 \mathrm{~g} / \mathrm{kg}$ dry matter of commercial $\alpha$-amylase (Termamyl SC, Novozymes, Bagsvaerd, Denmark) was added, and the mash was heated to $100{ }^{\circ} \mathrm{C}$ and liquefied for $90 \mathrm{~min}$. After the liquefying steps were completed, the resulting mash was cooled to a saccharification temperature $\left(50{ }^{\circ} \mathrm{C}\right)$, and Spirizyme Fuel (Novozymes, Bagsvaerd, Denmark) was added at $0.5 \mathrm{~g} / \mathrm{kg}$ dry matter. This saccharification step was aseptically performed for $24 \mathrm{~h}$ [45]. The chemically saccharified cassava hydrolysates were used for fermentation experiments.

\section{Determination of dry cell weight and metabolites}

We measured the cell growth based on optical density using a spectrophotometer (OPTIZEN POP; Mecasys, Daejeon, Korea) set at $600 \mathrm{~nm}\left(\mathrm{OD}_{600}\right)$. Dry cell weight (DCW) was estimated using a conversion factor of 0.50 $\mathrm{g}_{\text {dry cell }} / \mathrm{L} / \mathrm{OD}_{600}$. Acetate, acetoin, ethanol, glucose, glycerol, and 2,3-BDO were measured using a high-performance liquid chromatography (1260 Infinity, Agilent, CO, USA) equipped with a BioRad Aminex HPX-87H column $(300 \mathrm{~mm} 7.8 \mathrm{~mm}, 5 \mu \mathrm{m}$; Bio-Rad, Hercules, CA, USA) and a $5 \mathrm{mM} \mathrm{H}_{2} \mathrm{SO}_{4}$ mobile phase set at a flow rate of $0.6 \mathrm{~mL} / \mathrm{min}$. Metabolites were quantified using a refractive index (RI) detector.

\section{Supplementary information}

Supplementary information accompanies this paper at https://doi. org/10.1186/s13068-019-1545-1.

Additional file 1. Additional tables and figures.

\section{Acknowledgements}

This work was supported by the Advanced Biomass R\&D Center (ABC) of Global Frontier Project funded by the Ministry of Science and ICT (20110031359). We are grateful to Christine Atkinson (University of Illinois at UrbanaChampaign) for proofreading and suggestions on the writing.

\section{Authors' contributions}

YG LEE conceived and designed the study, analyzed and interpreted data, conducted experiments, and wrote the manuscript. JH Seo analyzed data and revised the manuscript. Both authors read and approved the final manuscript.

\section{Funding}

This study is funded by National Research Foundation of Korea (2011-0031359).

Availability of data and materials

Data made available to all interested researchers upon request.
Ethics approval and consent to participate Not applicable.

\section{Consent for publication}

Not applicable.

\section{Competing interests}

The authors declare they have no competing interests.

Received: 27 December 2018 Accepted: 17 August 2019

Published online: 29 August 2019

\section{References}

1. Zhang Y, Liu D, Chen Z. Production of C2-C4 diols from renewable bioresources: new metabolic pathways and metabolic engineering strategies. Biotechnol Biofuels. 2017;10(1):299.

2. Ji X-J, Huang H, Ouyang P-K. Microbial 2,3-butanediol production: a stateof-the-art review. Biotechnol Adv. 2011;29(3):351-64.

3. Celińska E, Grajek W. Biotechnological production of 2,3-butanediolcurrent state and prospects. Biotechnol Adv. 2009;27(6):715-25.

4. Köpke M, Mihalcea C, Liew F, Tizard JH, Ali MS, Conolly JJ, Al-Sinawi B, Simpson SD. 2,3-Butanediol production by acetogenic bacteria, an alternative route to chemical synthesis, using industrial waste gas. Appl Environ Microbiol. 2011;77(15):5467-75.

5. Christensen CH, Rass-Hansen J, Marsden CC, Taarning E, Egeblad K. The renewable chemicals industry. Chemsuschem. 2008;1(4):283-9.

6. Burk MJ, Van Dien SJ, Burgard AP, Niu W. Compositions and methods for the biosynthesis of 1,4-butanediol and its precursors. Google Patents; 2011

7. Radoš D, Carvalho AL, Wieschalka S, Neves AR, Blombach B, Eikmanns BJ, Santos $\mathrm{H}$. Engineering Corynebacterium glutamicum for the production of 2,3-butanediol. Microb Cell Fact. 2015;14(1):171.

8. Sheldon RA. Green solvents for sustainable organic synthesis: state of the art. Green Chem. 2005;7(5):267-78.

9. Li N, Yan W, Yang P, Zhang H, Wang Z, Zheng J, Jia S, Zhu Z. Direct C-C coupling of bio-ethanol into 2,3-butanediol by photochemical and photocatalytic oxidation with hydrogen peroxide. Green Chem. 2016:18(22):6029-34.

10. Um J, Kim DG, Jung M-Y, Saratale GD, Oh M-K. Metabolic engineering of Enterobacter aerogenes for 2,3-butanediol production from sugarcane bagasse hydrolysate. Bioresour Technol. 2017;245:1567-74.

11. Li L, Li K, Wang Y, Chen C, Xu Y, Zhang L, Han B, Gao C, Tao F, Ma C. Metabolic engineering of Enterobacter cloacae for high-yield production of enantiopure (2R,3R)-2,3-butanediol from lignocellulose-derived sugars. Metab Eng. 2015;28:19-27.

12. Ma C, Wang A, Qin J, Li L, Ai X, Jiang T, Tang H, Xu P. Enhanced 2,3-butanediol production by Klebsiella pneumoniae SDM. Appl Microb Biotechnol. 2009;82(1):49-57.

13. Jung S-G, Jang J-H, Kim A-Y, Lim M-C, Kim B, Lee J, Kim Y-R. Removal of pathogenic factors from 2,3-butanediol-producing Klebsiella species by inactivating virulence-related wabG gene. Appl Microb Biotechnol. 2013;97(5):1997-2007.

14. Shrivastav A, Lee J, Kim H-Y, Kim Y-R. Recent insights in the removal of Klebseilla pathogenicity factors for the industrial production of 2,3-butanediol. J Microbiol Biotechnol. 2013:23(7):885-96.

15. Kim SJ, Sim HJ, Kim JW, Lee YG, Park YC, Seo JH. Enhanced production of 2,3-butanediol from xylose by combinatorial engineering of xylose metabolic pathway and cofactor regeneration in pyruvate decarboxylase-deficient Saccharomyces cerevisiae. Bioresour Technol. 2017;245(Pt B):1551-7.

16. Choi EJ, Kim JW, Kim SJ, Seo SO, Lane S, Park YC, Jin YS, Seo JH. Enhanced production of 2,3-butanediol in pyruvate decarboxylase-deficient Saccharomyces cerevisiae through optimizing ratio of glucose/galactose. Biotechnol J. 2016;11(11):1424-32.

17. Nan H, Seo S-O, Oh EJ, Seo J-H, Cate JH, Jin Y-S. 2,3-Butanediol production from cellobiose by engineered Saccharomyces cerevisiae. Appl Microb Biotechnol. 2014;98(12):5757-64.

18. Chin Y-W. Comparison of ethanol fermentation properties between laboratorial and industrial yeast strains using cassava hydrolysate. Korean J Microbiol Biotechnol. 2012;40(3):220-5. 
19. Lee $Y-G$, Jin $Y-S$, Cha $Y-L$, Seo J-H. Bioethanol production from cellulosic hydrolysates by engineered industrial Saccharomyces cerevisiae. Bioresour Technol. 2017;228:355-61.

20. Lee H-J, Kim S-J, Yoon J-J, Kim KH, Seo J-H, Park Y-C. Evolutionary engineering of Saccharomyces cerevisiae for efficient conversion of red algal biosugars to bioethanol. Bioresour Technol. 2015;191:445-51.

21. de Smidt O, du Preez JC, Albertyn J. Molecular and physiological aspects of alcohol dehydrogenases in the ethanol metabolism of Saccharomyces cerevisiae. FEMS Yeast Res. 2012;12(1):33-47.

22. Hong K-K, Nielsen J. Metabolic engineering of Saccharomyces cerevisiae: a key cell factory platform for future biorefineries. Cell Mol Life Sci. 2012;69(16):2671-90.

23. Kim SJ, Seo SO, Park YC, Jin YS, Seo JH. Production of 2,3-butanediol from xylose by engineered Saccharomyces cerevisiae. J Biotechnol. 2014;192(Pt B):376-82.

24. Kim S-J, Seo S-O, Jin Y-S, Seo J-H. Production of 2,3-butanediol by engineered Saccharomyces cerevisiae. Bioresour Technol. 2013;146:274-81.

25. Pronk JT, Yde Steensma H, van Dijken JP. Pyruvate metabolism in Saccharomyces cerevisiae. Yeast. 1996;12(16):1607-33.

26. Flikweert MT, de Swaaf M, van Dijken JP, Pronk JT. Growth requirements of pyruvate-decarboxylase-negative Saccharomyces cerevisiae. FEMS Microbiol Lett. 1999:174(1):73-9.

27. Kim JW, Kim J, Seo SO, Kim KH, Jin YS, Seo JH. Enhanced production of 2,3-butanediol by engineered Saccharomyces cerevisiae through fine-tuning of pyruvate decarboxylase and NADH oxidase activities. Biotechnol Biofuels. 2016;9:265

28. Kim S, Hahn J-S. Efficient production of 2,3-butanediol in Saccharomyces cerevisiae by eliminating ethanol and glycerol production and redox rebalancing. Metab Eng. 2015;31:94-101.

29. Steensmati H, Van Dijkent JP, Pronkt JT. Pyruvate decarboxylase: an indispensable enzyme for growth of Saccharomyces cerevisiae on glucose. Yeast. 1996;12:247-57

30. De Smidt O, Du Preez JC, Albertyn J. The alcohol dehydrogenases of Saccharomyces cerevisiae: a comprehensive review. FEMS Yeast Res. 2008:8(7):967-78.

31. Ng C, Lee J, Oh M-K, Jung M-Y. Production of 2,3-butanediol in Saccharomyces cerevisiae by in silico aided metabolic engineering. Microb Cell Fact. 2012;11(1):68.

32. Kim JW, Seo SO, Zhang GC, Jin YS, Seo JH. Expression of Lactococcus lactis $\mathrm{NADH}$ oxidase increases 2,3-butanediol production in Pdc-deficient Saccharomyces cerevisiae. Bioresour Technol. 2015;191:512-9.

33. Białkowska AM. Strategies for efficient and economical 2,3-butanediol production: new trends in this field. World J Microbiol Biotechnol. 2016;32(12):200.

34. Choi G-W, Um H-J, Kim Y, Kang H-W, Kim M, Chung B-W, Kim Y-H. Isolation and characterization of two soil derived yeasts for bioethanol production on Cassava starch. Biomass Bioenergy. 2010;34(8):1223-31.
35. Jones DT, Shirley M, Wu X, Keis S. Bacteriophage infections in the industrial acetone butanol(AB) fermentation process. J Mol Microbiol Biotechnol. 2000;2(1):21-6.

36. Tsai CS, Kong II, Lesmana A, Million G, Zhang GC, Kim SR, Jin YS. Rapid and marker-free refactoring of xylose-fermenting yeast strains with Cas9/ CRISPR. Biotechnol Bioeng. 2015;112(11):2406-11.

37. Ishii J, Morita K, Ida K, Kato H, Kinoshita S, Hataya S, Shimizu H, Kondo A, Matsuda F. A pyruvate carbon flux tugging strategy for increasing 2,3-butanediol production and reducing ethanol subgeneration in the yeast Saccharomyces cerevisiae. Biotechnol Biofuels. 2018;11(1):180.

38. Yang T, Rao Z, Zhang X, Xu M, Xu Z, Yang ST. Metabolic engineering strategies for acetoin and 2,3-butanediol production: advances and prospects. Crit Rev Biotechnol. 2017;37(8):990-1005.

39. Moon SK, Kim DK, Park J, Min J, Song H. Development of a semi-continuous two-stage simultaneous saccharification and fermentation process for enhanced 2,3-butanediol production by Klebsiella oxytoca. Lett Appl Microbiol. 2018;66(4):300-5.

40. Zhang G-C, Kong II, Kim H, Liu J-J, Cate JH, Jin Y-S. Construction of a quadruple auxotrophic mutant of an industrial polyploid Saccharomyces cerevisiae strain by using RNA-guided Cas9 nuclease. Appl Environ Microbiol. 2014;80(24):7694-701.

41. Kim J-W. Cofactor and pathway engineering of Saccharomyces cerevisiae for enhanced production of 2,3-butanediol. PhD Thesis. Seoul National University; 2016.

42. De Felipe FL, Kleerebezem M, de Vos WM, Hugenholtz J. Cofactor engineering: a novel approach to metabolic engineering in Lactococcus lactis by controlled expression of NADH oxidase. J Bacteriol. 1998;180(15):3804-8.

43. Postma E, Verduyn C, Scheffers WA, Van Dijken JP. Enzymic analysis of the crabtree effect in glucose-limited chemostat cultures of Saccharomyces cerevisiae. Appl Environ Microbiol. 1989;55(2):468-77.

44. Bradford MM. A rapid and sensitive method for the quantitation of microgram quantities of protein utilizing the principle of protein-dye binding. Anal Biochem. 1976;72(1-2):248-54

45. Moon S-K, Wee Y-J, Choi G-W. Utilization of by-products derived from bioethanol production process for cost-effective production of lactic acid. J Ind Microbiol Biotechnol. 2014;41(10):1525-31.

\section{Publisher's Note}

Springer Nature remains neutral with regard to jurisdictional claims in published maps and institutional affiliations.
Ready to submit your research? Choose BMC and benefit from:

- fast, convenient online submission

- thorough peer review by experienced researchers in your field

- rapid publication on acceptance

- support for research data, including large and complex data types

- gold Open Access which fosters wider collaboration and increased citations

- maximum visibility for your research: over 100M website views per year

At BMC, research is always in progress.

Learn more biomedcentral.com/submissions 